Khalid Al-Hezaimi

Ivan Rudek

Khalid S. Al-Hamdan

Fawad Javed

Nasser Nooh

Hom-Lay Wang

\section{Efficacy of using a dual layer of membrane (dPTFE placed over collagen) for ridge preservation in fresh extraction sites: a micro-computed tomographic study in dogs}

Key words: collagen membrane, high-density polytetrafluoroethylene membrane, micro-computed tomography, ridge preservation

Khalid Al-Hezaimi, Khalid S. Al-Hamdan, Fawad Javed, Hom-Lay Wang, Engineer Abdullah Bugshan Research Chair for Growth Factors and Bone Regeneration, 3D Imaging and Biomechanical Lab, College of Applied Medical Sciences, King Saud University, Riyadh, Saudi Arabia

Khalid Al-Hezaimi, Khalid S. Al-Hamdan, Department of Periodontics and Community Dentistry, College of Dentistry, King Saud University, Riyadh, Saudi Arabia

Nasser Nooh, Department of Oral and Maxillofacial Surgery, King Saud University, Riyadh, Saudi Arabia

Ivan Rudek, School of Dentistry, University of Michigan, Ann Arbor, MI, USA

Hom-Lay Wang, Department of Periodontics and Oral Medicine, University of Michigan School of Dentistry, Ann Arbor, MI, USA

\section{Corresponding author:}

Dr Khalid Al-Hezaimi

Engineer Abdullah Bugshan Research Chair for Growth Factors and Bone Regeneration

3D Imaging and Biomechanical Lab, College of Applied Medical Sciences, King Saud University Riyadh, Saudi Arabia

Tel.: +966502303000

Fax: +966 14678639

e-mail: hezaimik16@gmail.com

Date:

Accepted 26 May 2012

To cite this article:

Al-Hezaimi K, Rudek I, Al-Hamdan KS, Javed F, Nooh N,

Wang H-L. Efficacy of using a dual layer of membrane (dPTFE placed over collagen) for ridge preservation in fresh extraction sites: A micro-computed tomographic study in dogs.

Clin. Oral Imp. Res. 24, 2013, 1152-1157

doi: 10.1111/j.1600-0501.2012.02526.x

\section{Abstract}

Objective: To assess if overbuilding the buccal plate or using a dual-layer socket grafting technique prevents alveolar bone resorption and enhances final ridge width, height, and volume after tooth loss in an animal model.

Material and methods: In eight beagle dogs bilateral second (P2)-, third (P3)-, and fourth (P4) premolars were endodontically treated. All bilateral mandibular first premolars and distal roots of P2, P3, and P4 were hemisectioned and atraumatically extracted. Animals were randomly divided into four groups: (i) Control-Socket alone, (ii) Particulate allograft in the alveolum, socket covered with high-density polytetrafluoroethylene (dPTFE) membrane and sutured over the alveolum, (iii) Particulate allograft in the alveolum and overbuilding the buccal plate, socket covered with dPTFE membrane and sutured over the alveolum, (iv) Particulate allograft in the alveolum and covered with dual layer (dPTFE placed over collagen membrane), and sutured over the alveolum. After 16 weeks, the animals were sacrificed. Mandibular blocks of the jaws were assessed for bone volume (BV), vertical bone height (VBH), alveolar ridge thickness, and bone mineral density (BMD) using micro-computed tomography.

Results: The BV in groups 1, 2, 3, and 4 was $169.5,207.57,242.4$, and $306.1 \mathrm{~mm}^{3}$, respectively. The VBH in groups $1,2,3$, and 4 was $4.2,6.4,6.2$, and $7.3 \mathrm{~mm}$, respectively. Ridge widths in groups 1 , 2,3 , and 4 were $5.45 \pm 0.75,5.91 \pm 0.86,6.05 \pm 0.63$, and $6.28 \pm 1.01 \mathrm{~mm}$, respectively. There was no significant difference in BMD between the groups.

Conclusions: The RP using a dual layer of membrane following tooth extraction results in more $\mathrm{BV}, \mathrm{VBH}$, and alveolar ridge width as compared to when a single layer of membrane is used.
Tooth extraction is a traumatic procedure that jeopardizes alveolar bone and surrounding soft tissues (Amler 1969; Araújo \& Lindhe 2005). During the healing process, the extraction socket is initially filled with blood and by the first-week of extraction, is replaced by granulation tissue (Amler 1969). By the 14th day of extraction, granulation tissue is replaced by connective tissue and osteoid bone starts appearing in the base of the socket. The socket gets completely filled with woven (bundle) bone by the fourth week of extraction (Amler 1969). Buccal bone remodeling following tooth extraction has been reported (Araújo \& Lindhe 2005); however, recent studies have shown that extraction of multiple contiguous teeth causes are more extensive buccal bone remodeling as compared to when a single tooth is extracted (Araújo \& Lindhe 2005; Al-Askar et al. 2011; Al-Hezaimi et al. 2011; Al-Shabeeb et al. 2011).

The use of ridge preservation protocols for the treatment of osseous defects is well established (Gapski et al. 2006; Neiva et al. 2008; Avila et al. 2010). A novel approach has been proposed and consists of overbuilding the buccal plate with bone grafting materials (Fickl et al. 2009a,b). The rationale behind this modification of the conventional socket grafting approach relies on the addition of extra material in the area of the ridge where bone resorption is known to be more marked (buccal and coronal), with the hope of compensating natural resorption phenomena. Two animal studies 
(Fickl et al. 2009a,b) volumetrically and histologically assessed the alterations of the ridge contour after socket preservation and buccal overbuilding primarily with soft tissue graft or a xenogenic bone filler. These studies (Fickl et al. 2009a,b) demonstrated that buccal overbuilding with these materials failed to prevent alterations in the alveolar ridge after tooth extraction.

Barrier membranes are widely used in alveolar ridge preservation procedures as they protect the adjacent soft tissues from cells that may impede new bone formation and may also improve the mechanical stability of the graft material (Mardas et al. 2011a,b; Vignoletti et al. 2012). Traditionally, collagen membranes are employed for ridge preservation protocols due to their hemostatic, chemostatic, and cell adhesive characteristics (Mardas et al. 2011a,b; Vignoletti et al. 2012); however, their fast resorption rate following exposure to the oral environment and requirement of primary closure over the socket (that may increase surgical complexity) have raised concerns over their usage. In this regard, high-density polytetrafluoroethylene (dPTFE) membranes were introduced which do not require primary closure. The smooth surface of dPTFE membranes and their small pore size $(0.2 \mu \mathrm{m})$ eases their removal, without the need for supplementary surgical procedures and prevents bacterial leakage into the tissues thereby facilitating bone preservation procedures (Bartee 1995; Bartee \& Carr 1995; Barber et al. 2009; Waasdorp \& Feldman 2011; Yun et al. 2011). However, a limitation of dPTFE is that the material has poor tissue adhesive properties which may sequentially jeopardize bone regeneration occurring underneath the membrane (Park et al. 2009).

The present study utilized a canine model to test the hypothesis that using collagen and dPTFE membrane as a "dual layer" surmounts their individualistic disadvantages thereby enhancing ridge preservation (RP) procedures around osseous defects. The aim of this experiment was to evaluate the effect of using a dual-layer membrane (dPTFE placed over collagen) for RP in fresh extraction sockets.

\section{Materials and methods}

\section{Ethical guidelines}

The research ethics review committee at the Engineer Abdullah Bugshan Research Chair for Growth Factors and Bone Regeneration, 3D Imaging and Biomechanical Lab., College of Applied Medical Sciences, Riyadh, Saudi Arabia, approved the study.

\section{Study animals}

Eight healthy female beagle dogs with a mean age and weight of $24 \pm 0.83$ months and $13.8 \pm 0.49$ kilograms $(\mathrm{kg})$, respectively, were used. The animals were kept in individual cages and vaccinated against hepatitis and rabies.

The non-surgical and surgical procedures were performed under general anesthesia using ketamine (10 milligrams [mg]/kg body weight) (Pfizer Limited, Kent, UK) and local anesthesia with xylocaine (with epinephrine $5 \mathrm{mg} / \mathrm{ml}$ ) (AstraZeneca LP for DENTSPLY Pharmaceutical, York, PA, USA). The dogs were kept in individual cages and on a soft diet throughout the study.

\section{Preoperative management}

One week before tooth extraction, all dogs underwent supragingival scaling using an ultrasonic scaler (NSK, Westborough, MA, USA). Intra-muscular (IM) injections of amoxicillin (25 mg/kg body weight) (Betamox LA; Norbrook Laboratory Limited, Newry, County Down, Northern Ireland) were administered at the day of surgery. The animals were draped and the surgical site was swabbed with an antiseptic solution (The Purdue Fredrick Company, Stamford, CT, USA).

\section{Root canal treatment and tooth extractions}

Under general anesthesia (Pfizer Limited) with adjunct buccal infiltration (AstraZeneca LP for DENTSPLY Pharmaceutical), non-surgical root canal treatment (RCT) was performed on bilateral mandibular second, third, and fourth premolars (P2, P3, and P4, respectively). Access cavity was prepared with a No. 2 size round tungsten bur (Brassler, Savannah, GA, USA) mounted on a highspeed hand piece (Dentsply, York, PA, USA). The root-canals were prepared with rotary files (Profile; Dentsply, Addlestone, UK) following initial instrumentation with K-type (JS Dental, Ridgefield, CT, USA) hand files. The root-canals were irrigated with $5.25 \%$ sodium hypochlorite and obturated with vertically condensed gutta percha and sealer (Pulp Canal Sealer EWT; SybronEndo, Orange, CA, USA). Peri-apical radiographs were taken to confirm accuracy of the RCT.

Eight weeks after RCT, bilateral mandibular first premolars (P1) were extracted atraumatically. Bilateral mandibular P2, P3, and P4 were hemisected using piezosurgery (Piezosurgery ${ }^{\circledR}$; Mectron, Columbus, OH, USA) and the distal roots were atraumatically extracted using forceps. The distal alveolus was currettaged to stimulate bleeding and eliminate remnants of the periodontal ligaments.

\section{Animal grouping}

Each tooth was randomly assigned to one of the four treatment groups by picking a paper marked either "Group1", "Group 2", "Group 3", or "Group 4" from a brown bag. Group 1: (Control), comprised of socket alone. Group 2: Particulate allograft ${ }^{\text {IIII }}$ placed in the alveolum, socket and covered with dPTFE membrane (Cytoplast ${ }^{\circledR}$ Barrier Membranes, TXT200; Osteogenics Biomedical, Lubbock, TX, USA); Group 3: Particulate allograft $\left(\right.$ Puros $^{\circledR}$ cancellous particulate allograft; Zimmer Dental, Carlsbad, CA, USA) placed in the alveolum and overbuilding the buccal plate and socket covered with dPTFE membrane /Cytoplast ${ }^{\circledR}$ Barrier Membranes, TXT-200); and Group 4: Particulate allograft (Puros ${ }^{\circledR}$ cancellous particulate allograft; Zimmer Dental) placed in the alveolum and covered with a dual layer of membrane, that is, a dPTFE membrane /Cytoplast $^{\circledR}$ Barrier Membranes, TXT-200) placed over collagen (Cytoplast ${ }^{\circledR}$ RTM Collagen, Osteogenics Biomedical, Inc. Germany). All defects were sutured over the alveolum using resorbable sutures (Ethicon Inc. VICRYL [Polyglactin 910] suture, Somerville, NJ, USA). (Fig. 1a-f)

Overall, 16 hemimandibles were treated that translated into a total of 16 sites per treatment group.

\section{Postoperative management and euthanasia}

All subjects received IM injections of amoxicillin $(5 \mathrm{mg} / \mathrm{kg}$ body weight once a day for 3 days) (Betamox LA, Norbrook Laboratory Limited); Plaque control procedures, which included topical application of a $0.2 \%$ chlorhexidine digluconate solution (GUM, Chicago, IL, USA) were performed twice a week for 4 months after surgery. After 2 weeks, the sutures were removed and periapical radiographs were also taken to assess the relationship of the implants with the adjacent vital structures. IM antibiotics (Betamox LA, Norbrook Laboratory Limited) were continued for 3 days after surgery as $25-50 \mathrm{mg} / \mathrm{kg}$ IM every $8 \mathrm{~h}$.

The subjects were sacrificed after 4 months with an overdose of $3 \%$ sodium pentobarbitol (Vortech Pharmaceuticals Limited, Dearborn, MI, USA).

\section{Jaw sectioning and micro-computed tomography analysis}

The jaw segments containing the extraction sockets were removed en block using an electric saw (SP 1600; Leica, Bannockburn, 

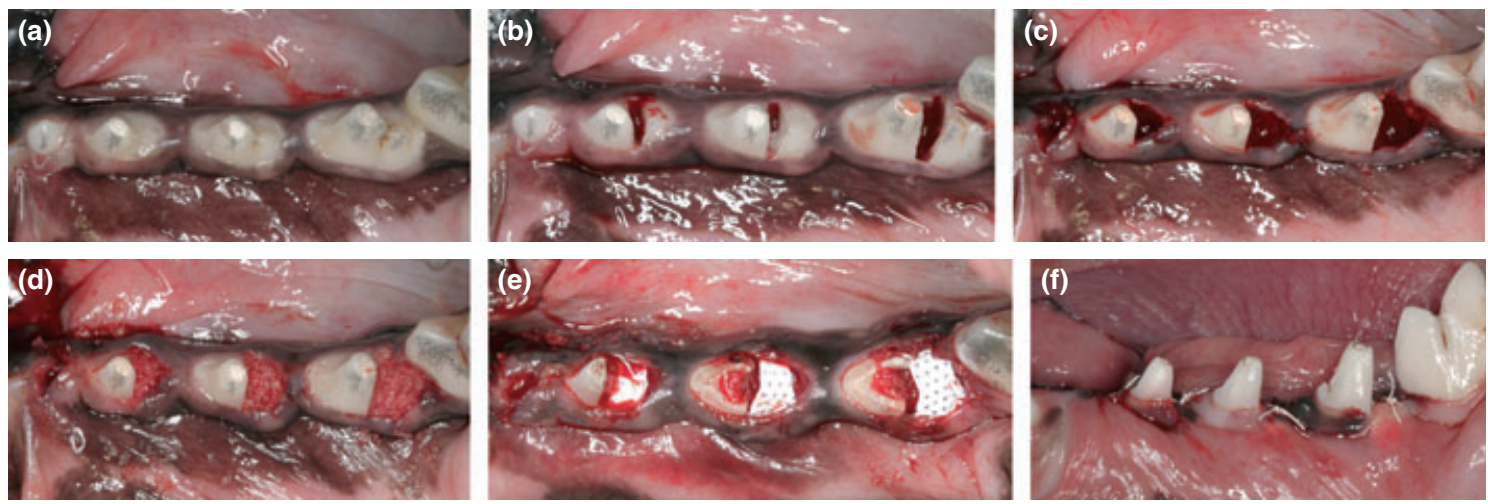

Fig. 1. (a) Preoperative clinical photograph. (b) Distal roots were hemisectioned and extracted with no dehiscence. (c) Shows the different sites with application of membrane alone, membrane and bone graft, dual-layer membrane, and bone graft material. (d) Primary closure was achieved. (e) for healing.

IL, USA); and fixed in 10\% neutral formalin solution. A three-dimensional analysis of the jaw samples was performed via a micro-computed tomography (micro-CT) scanner (SkyScan 1172, CT-Analyser, Version 1.11.4.2+; Kontich, Belgium). The $\mathrm{x}$-ray generator of the micro-CT was operated at an accelerated potential of $101 \mathrm{kV}$ with a beam current of $96 \mu \mathrm{A}$ using an aluminum filter with a resolution of $37.41 \mu \mathrm{m}$ pixels.

Volumetric measurements (bone volume $[\mathrm{BV}]$, bone mineral density [BMD], alveolar ridge width (buccolingual thickness) of the alveolar ridge and vertical bone height [VBH]) were performed following the selection of a three-dimensional region of interest on the micro-CT scans (SkyScan 1172, CT-Analyser, Version 1.11.4.2+). The VBH was determined by measuring the linear distance from the center of the crest till the most apical region of the socket.

\section{Statistical analysis}

Statistical analysis was performed using statistical software (SPSS, Version 18.00; Chicago, IL, USA). Differences between the BV, bone mineral density, alveolar ridge width and $\mathrm{VBH}$ between the groups were assessed using one-way analysis of variance (ANOVA). For multiple comparisons, Bonferroni post hoc test was performed. P-values less than 0.05 were considered statistically significant.

\section{Results}

\section{Alveolar ridge width}

Alveolar ridge width (at $2 \mathrm{~mm}$ thickness) in groups 1, 2, 3, and 4 were $5.45 \pm 0.75$, $5.91 \pm 0.86,6.05 \pm 0.63$, and $6.28 \pm 1.01 \mathrm{~mm}$, respectively. The mean width of the alveolar ridge in Group 1 and Group 4 was $5.45 \pm 0.75$ and $6.28 \pm 1.01 \mathrm{~mm}$, respectively
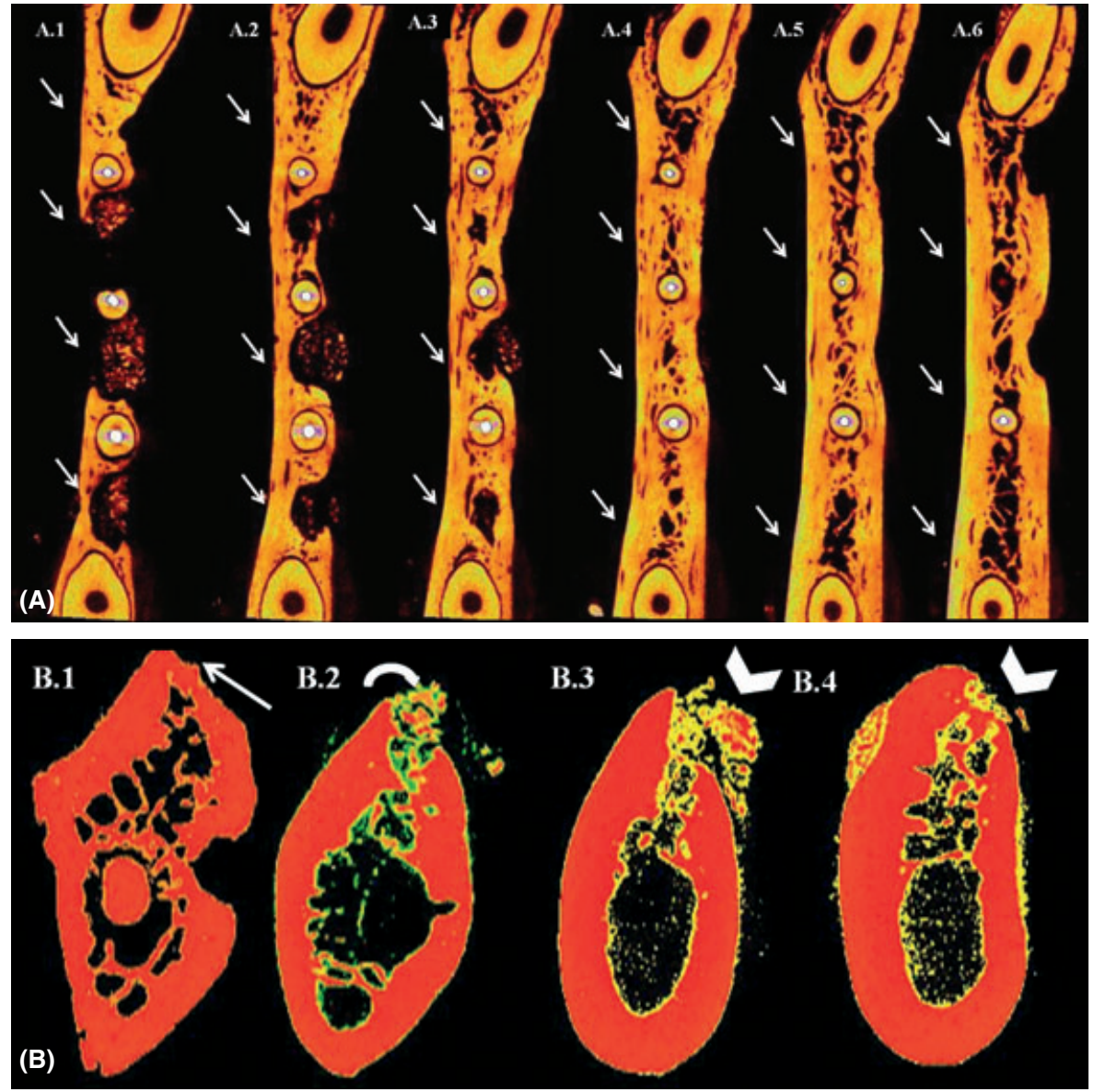

Fig. 2. (A) A series of reconstructed axial images illustrating measurements of alveolar ridge thickness and volume in each group site at different levels using micro-computed tomographic images. (A.1) at $1 \mathrm{~mm}$ and the arrows points to the group sites, (A.2) at $2 \mathrm{~mm},($ A.3) at $3 \mathrm{~mm},($ A.4) at $4 \mathrm{~mm},($ A.5) at $5 \mathrm{~mm}$, and (A.6) at $6 \mathrm{~mm}$. It is evident there is significance in the ridge width in the first $3 \mathrm{~mm}$. (a) control, (b) allograft in alveolum and covered with high-density polytetrafluoroethylene (dPTFE) membrane, (c) allograft placed in alveolum, buccal plate overbuilt with allograft and covered with dPTFE membrane, and (d) allograft in alveolum covered with a dual-layer membrane (dPTFE placed over collagen membrane). (B) Series of reconstructed sagital sections images illustrating the measurements of the alveolar ridge thickness and volume at each group. (B.1) control, (B.2) allograft in alveolum and covered with dPTFE membrane, (B.3) allograft placed in alveolum, buccal plate overbuilt with allograft and covered with dPTFE membrane, and (B.4) allograft in alveolum covered with a dual-layer membrane (dPTFE placed over collagen membrane).

$(P=0.03)$. There were no significant differences in the alveolar ridge widths between groups 1, 2, and 3 (Fig. 2A.1-6).
The median and range for alveolar ridge width (up to the $4 \mathrm{~mm}$ thickness) is shown in Table 1 . 


\section{Bone volume}

The mean BV in groups 1, 2, 3, and 4 was $188.7 \pm 69.29, \quad 214.55 \pm 67.97, \quad 267.97 \pm 79$, and $339.46 \pm 112.88 \mathrm{~mm}^{3}$, respectively, as shown in Table 2. Osseous defects in Group 4 showed significantly higher buccal bone volumes as compared with in Group 1 and Group $2(P=0.0001)$. The BV in Group 3 was significantly higher as compared to defects in Group $1(P=0.03)$ (Fig. 2B.1-4). The median BV for groups $1,2,3$, and 4 is shown in Table 3 .

Bone mineral density and vertical bone height There was no significant difference in the mean BMD between groups 1, 2, 3, and 4 as shown in Table 2. The median BMD in groups $1,2,3$, and 4 is shown in Table 3 .
The mean VBH in groups $1,2,3$, and 4 was $4.18 \pm 0.43, \quad 6.33 \pm 0.81, \quad 6.62 \pm 1.08, \quad$ and $7.68 \pm 1.53 \mathrm{~mm}$, respectively. The VBH was highest among sites in Group 4 as compared with sockets in Group $1(P=0.0001)$, Group $2(P=0.0001)$, and Group-3 $(P=0.03)$ as shown in Table 2. The median BMD and $\mathrm{VBH}$ is shown in Table 3.

\section{Discussion}

The present results showed that using a dual layer of membrane (dPTFE placed over collagen membrane) was effective in RP in contrast to when regenerative protocols were performed using either a single membrane or without a barrier membrane. These results

Table 1. Median (range) alveolar ridge width (up to $4 \mathrm{~mm}$ thickness) in groups $1,2,3$, and 4

\begin{tabular}{|c|c|c|c|c|}
\hline Alveolar ridge width & $\begin{array}{l}\text { Group-1 } \\
\text { Median } \\
\text { (Range) }\end{array}$ & $\begin{array}{l}\text { Group-2 } \\
\text { Median } \\
\text { (Range) }\end{array}$ & $\begin{array}{l}\text { Group-3 } \\
\text { Median } \\
\text { (Range) }\end{array}$ & $\begin{array}{l}\text { Group-4 } \\
\text { Median } \\
\text { (Range) }\end{array}$ \\
\hline At $1 \mathrm{~mm}$ & $\begin{array}{l}3.70 \\
(2.5-5.4)\end{array}$ & $\begin{array}{l}4.05 \\
(1.7-5.9)\end{array}$ & $\begin{array}{l}5 \\
(2.40-6.40)\end{array}$ & $\begin{array}{l}5.6 \\
(4.40-6.90)\end{array}$ \\
\hline At $2 \mathrm{~mm}$ & $\begin{array}{l}5.25 \\
(3.40-7.40)\end{array}$ & $\begin{array}{l}4.8 \\
(2.70-6.40)\end{array}$ & $\begin{array}{l}5.70 \\
(4.50-7.30)\end{array}$ & $\begin{array}{l}5.95 \\
(5.30-7.50)\end{array}$ \\
\hline At $3 \mathrm{~mm}$ & $\begin{array}{l}6.20 \\
(4.20-8.30)\end{array}$ & $\begin{array}{l}5.45 \\
(4.40-7.30)\end{array}$ & $\begin{array}{c}6.15 \\
(5-7.70)\end{array}$ & $\begin{array}{l}6.8 \\
(5.70-7.90)\end{array}$ \\
\hline At $4 \mathrm{~mm}$ & $\begin{array}{l}6.6 \\
(5.60-8.50)\end{array}$ & $\begin{array}{l}5.85 \\
(4.60-7.70)\end{array}$ & $\begin{array}{l}6.2 \\
(5.10-7.70)\end{array}$ & $\begin{array}{l}7.3 \\
(6.20-8-20)\end{array}$ \\
\hline
\end{tabular}

Table 2. Mean buccal bone volume, bone mineral density, and vertical bone height of newly formed bone in the socket among the treatment groups

\begin{tabular}{|c|c|c|c|c|}
\hline & $\begin{array}{l}\text { Group-1 } \\
\text { (Mean } \pm \text { SD) }\end{array}$ & $\begin{array}{l}\text { Group-2 } \\
(\text { Mean } \pm \text { SD) }\end{array}$ & $\begin{array}{l}\text { Group-3 } \\
\text { (Mean } \pm \text { SD) }\end{array}$ & $\begin{array}{l}\text { Group-4 } \\
(\text { Mean } \pm \text { SD) }\end{array}$ \\
\hline & & & 1 & \\
\hline Bone volume (in $\mathrm{mm}^{3}$ ) & $188.7 \pm 69.29^{*}$ & $214.55 \pm 67.97$ & $267.97 \pm 79.78$ & $\begin{array}{l}339.46 \pm 112.88^{*} \\
\ddagger\end{array}$ \\
\hline $\begin{array}{l}\text { Bone mineral density (in g/ } \\
\mathrm{mm}^{3} \text { ) }\end{array}$ & $0.0141 \pm 0.0079$ & $0.0135 \pm 0.0070$ & $\begin{array}{l}0.0140 \pm 0.0076 \\
\dagger\end{array}$ & $0.0147 \pm 0.0073$ \\
\hline $\begin{array}{l}\text { Vertical bone height (in } \\
\mathrm{mm} \text { ) }\end{array}$ & $4.18 \pm 0.43^{\S}$ & $6.33 \pm 0.81$ & $6.62 \pm 1.08$ & $7.68 \pm 1.53^{\S}$ \\
\hline
\end{tabular}

${ }^{*} P<0.001 ;$

${ }^{\dagger} P<0.001 ;$

${ }^{\ddagger} P<0.05$;

${ }^{\S} P<0.001$.

Table 3. Median (range) buccal bone volume, bone mineral density, and vertical bone height of newly formed bone in the socket among the treatment groups

\begin{tabular}{lcccc}
\hline & $\begin{array}{l}\text { Group-1 } \\
\text { Median (Range) }\end{array}$ & $\begin{array}{l}\text { Group-2 } \\
\text { Median (Range) }\end{array}$ & $\begin{array}{l}\text { Group-3 } \\
\text { Median (Range) }\end{array}$ & $\begin{array}{l}\text { Group-4 } \\
\text { Median (Range) }\end{array}$ \\
\hline $\begin{array}{l}\text { Bone volume } \\
\text { (in } \mathrm{mm}^{3} \text { ) }\end{array}$ & $169.5(145.1-440.3)$ & $207.57(135-411)$ & $242.4(184.6-488.6)$ & $306.1(261.75-703.9)$ \\
$\begin{array}{l}\text { Bone mineral } \\
\text { density } \\
\text { (in } \mathrm{g} / \mathrm{mm}^{3} \text { ) }\end{array}$ & $0.01(0.01-0.04)$ & $0.01(0.01-0.04)$ & $0.01(0.01-0.04)$ & $0.01(0.01-0.04)$ \\
$\begin{array}{l}\text { Vertical bone } \\
\text { height } \\
\text { (in } \mathrm{mm} \text { ) }\end{array}$ & $4.2^{*}(3.20-4.9)$ & $6.4(5.1-8.2)$ & $6.2(5.1-8.4)$ & $7^{*}(5.2-10.6)$ \\
\hline$* P=0.0001$ & & & & \\
\hline
\end{tabular}

may be explained by the fact that the perks of collagen membranes (that exhibit optimal behavior toward soft-tissue responses) and dPTFE membrane (possessing optimal durability and antimicrobial effects) when used as a "dual layer" are summed up thereby promoting new bone formation as compared with when each membrane type is used alone (Fickl et al. 2009a; Annen et al. 2011). It may also be postulated that placement of an dPTFE membrane over collagen further stabilizes the graft at the defect site thereby augmenting new bone formation. In a recent case series, Yun et al. (2011) investigated the effect of using a dual layer of membrane (dPTFE placed over collagen membrane) on RP around immediate implants using scanning electron microscopy (SEM). In both cases, clinical and radiological results showed ample amount of new bone formation around the immediate implants (Yun et al. 2011). Moreover, the SEM results showed significantly lower bacterial count on the inner aspect of the dPTFE membrane as compared with the outer surface (Yun et al. 2011). This suggests that the dPTFE membrane provides a reasonably microbe-free environment to the underlying collagen membrane thereby facilitating its chemostatic and cell adhesive properties. The present micro-CT results are in accordance with the SEM results by Yun et al. (2011) since BV, thickness of alveolar ridge, and VBH were significantly higher in sockets covered with a dual-layer membrane (dPTFE placed over collagen) as compared with those covered merely with a single membrane. A reasonably microbe-free environment may also promote healing under the collagen membrane and promote new bone formation. However, further studies are warranted to identify the microbial specie that are associated with extraction sockets covered with a dual-layer membrane as compared with those covered merely with a single layer of membrane.

Different bone grafting materials with varying densities have been used in RP procedures (Thaller et al. 1993; Gomes et al. 2006; Scarano et al. 2006). It may therefore be argued that besides the type of barrier membrane, BMD of the bone graft material used may also influence bone formation. To overcome this confounding factor, we used a standard bone allograft in all extraction sockets in the present experiment. It is notable that there were no significant differences among the groups in terms of BMD. This parameter further confirms our hypothesis that a dual layer of membrane (dPTFE placed over collagen) significantly contributes in RP as compared with when a single layer of barrier membrane is used. 
A limitation of the present experiment is that socket walls in all groups were intact. Therefore, it may be pondered that presence of an osseous defect or a pathological lesion within or around the extraction socket may hamper new bone formation regardless of whether RP procedures were performed utilizing a single or dual layer of membrane. It is hypothesized that overbuilding of buccal plate with excess bone graft material assists in new bone formation. The present results support this hypothesis to an extent as sites with overfilled buccal plates and covered with dPTFE membrane (Group 3) showed significantly more bone formation as compared with sites in the control group (Group 1). However, it is noteworthy that sites with allograft covered with a dual layer of membrane (Group 4) displayed significantly higher $\mathrm{BV}, \mathrm{VBH}$, and ridge thickness as compared with sockets in Group 3. This suggests that placement of a dual layer

\section{References}

Al-Askar, M., O'Neill, R., Stark, P.C., Griffin, T., Javed, F. \& Al-Hezaimi, K. (2011) Effect of single and contiguous teeth extractions on alveolar bone remodeling: a study in dogs. Clinical Implant Dentistry and Related Research. [Epub ahead of print].

Al-Hezaimi, K., Javed, F., Ali, T.S., Al-Askar, M. \& Al-Rasheed, A. (2012) Rapidly progressive periodontal disease associated with human immunodeficiency virus. Journal of the College of Physicians and Surgeons-Pakistan 22: 186188.

Al-Hezaimi, K., Levi, P., Rudy, R., Al-Jandan, B. \& Al-Rasheed, A. (2011) An extraction socket classification developed using analysis of bone type and blood supply to the buccal bone in monkeys. The International Journal of Periodontics and Restorative Dentistry 31: 421-427.

Al-Shabeeb, M.S., Al-Askar, M., Al-Rasheed, A., Babay, N., Javed, F., Wang, H.L. \& Al-Hezaimi, K. (2011) Alveolar bone remodeling around immediate implants placed in accordance with the extraction socket classification-a three-dimensional microcomputed tomography analysis. Journal of Periodontology. [Epub ahead of print].

Amler, M.H. (1969) The time sequence of tissue regeneration in human extraction wounds. Oral Surgery Oral Medicine Oral Pathology 27: 309-318.

Annen, B.M., Ramel, C.F., Hämmerle, C.H. \& Jung, R.E. (2011) Use of a new cross-linked collagen membrane for the treatment of peri-implant dehiscence defects: a randomised controlled double-blinded clinical trial. European Journal of Oral Implantology 4: 87-100.

Araújo, M.G. \& Lindhe, J. (2005) Dimensional ridge alterations following tooth extraction. An experimental study in the dog. Journal of Clinical Periodontology 32: 212-218.

Avila, G., Neiva, R., Misch, C.E., Galindo-Moreno, P., Benavides, E., Rudek, I. \& Wang, H.L. (2010) Clinical and histologic outcomes after the use of a novel allograft for maxillary sinus augmenta- of membrane over bone graft yields more promising results in terms of RP as compared with when excessive graft material is used and covered with a single membrane. The Fickl studies (Fickl et al. 2009a,b) also showed that overbuilding the buccal process of alveolar bone with excess graft material is an ineffective technique for RP. The present study supports the results by Fickl (Fickl et al. 2009a,b); nevertheless, should buccal overbuilding with excess graft material and using a dual layer of membrane support alveolar RP at compromised sites (such as extraction sockets with a critical size defect) necessitates further investigations. Studies on humans have shown that systemic disease (such as poorly controlled diabetes mellitus and acquired immune deficiency syndrome) and tobacco habits (such as cigarette smoking) jeopardize periodontal health and may also negatively influence the outcome of periodontal therapy (Javed et al.

2007, 2012; Al-Hezaimi et al. 2012). It is tempting to speculate that the efficacy of novel $\mathrm{RP}$ techniques (such as those described in the present study) may be compromised in immunocompromised individuals and habitual tobacco-users. However, further studies are warranted in this regard.

Within the limits of the present investigation, it is concluded that RP using a dual layer of membrane following tooth extraction results in more $\mathrm{BV}, \mathrm{VBH}$, and alveolar ridge width as compared with when a single layer of membrane is used.

\section{Acknowledgement: Conflict of} interest and financial disclosure: The authors declare that they have no conflicts of interest and there was no external source of funding for the present study.

tion: a case series. Implant Dentistry 19: 330-341.

Barber, H.D., Lignelli, J., Smith, B.M. \& Bartee, B.K. (2009) Using a dense PTFE membrane without primary closure to achieve bone and tissue regeneration. Journal of Oral \& Maxillofacial Surgery 65: 748-752.

Bartee, B.K. (1995) The use of high-density polytetrafluoroethylene membrane to treat osseous defects: clinical reports. Implant Dentistry 4: 21-26.

Bartee, B.K. \& Carr, J.A. (1995) Evaluation of a high-density polytetrafluoroethylene (n-PTFE) membrane as a barrier material to facilitate guided bone regeneration in the rat mandible. Journal of Oral Implantology 21: 88-95.

Fickl, S., Schneider, D., Zuhr, O., Hinze, M., Ender, A., Jung, R.E. \& Hürzeler, M.B. (2009b) Dimensional changes of the ridge contour after socket preservation an buccal overbuilding: an animal study. Journal of Clinical Periodontology 36: 442-448.

Fickl, S., Zuhr, O., Wachtel, H., Kebschull, M. \& Hürzeler, M.B. (2009a) Hard tissue alterations after socket preservation with additional buccal overbuilding: a study in the beagle dog. Journal of Clinical Periodontology 36: 898-904.

Gapski, R., Neiva, R., Oh, T.J. \& Wang, H.L. (2006) Histologic analyses of human mineralized bone grafting material in sinus elevation procedures: a case series. The International Journal of Periodontics and Restorative Dentistry 26: 59-69.

Gomes, M.F., Abreu, P.P., Morosolli, A.R.C., Araújo, M.M. \& Goulart, M.G.V. (2006) Densitometric analysis of the autogenous demineralized dentin matrix on the dental socket wound healing process in humans. Brazilian Oral Research 20: $324-330$.

Javed, F., Al-Rasheed, A., Almas, K., Romanos, G.E. \& Al-Hezaimi, K. (2012) Effect of cigarette smoking on the clinical outcomes of periodontal surgical procedures. The American Journal of the Medical Sciences 343: 78-84.
Javed, F., Näsström, K., Benchimol, D., Altamash, M., Klinge, B. \& Engström, P.E. (2007) Comparison of periodontal and socioeconomic status between subjects with type 2 diabetes mellitus and non-diabetic controls. Journal of Periodontology 78: 2112-2119.

Mardas, N., D'Aiuto, F., Mezzomo, L., Arzoumanidi, M. \& Donos, N. (2011a) Radiographic alveolar bone changes following ridge preservation with two different biomaterials. Clinical Oral Implants Research 22: 416-423.

Mardas, N., D'Aiuto, F., Mezzomo, L., Arzoumanidi, M. \& Donos, N. (2011b) Alveolar ridge preservation with guided bone regeneration and a synthetic bone substitute or a bovine-derived xenograft: a randomized, controlled clinical trial. Clinical Oral Implants Research 22: 416423.

Neiva, R.F., Tsao, Y.P., Eber, R., Shotwell, J., Billy, E. \& Wang, H.L. (2008) Effects of a putty-form hydroxyapatite matrix combined with the synthetic cell-binding peptide P-15 on alveolar ridge preservation. Journal of Periodontology 79: 291299.

Park, S.H., Brooks, S.L., Oh, T.J. \& Wang, H.L. (2009) Effect of ridge morphology on guided bone regeneration outcome: conventional tomographic study. Journal of Periodontology 80: 1231-1236.

Scarano, A., Degidi, M., Iezzi, G., Pecora, G., Piattelli, M., Orsini, G., Caputi, S., Perrotti, V., Mangano, C. \& Piattelli, A. (2006) Maxillary sinus augmentation with different biomaterials: a comparative histologic and histomorphometric study in man. Implant Dentistry 15: 197.

Thaller, S.R., Hoyt, J., Borjeson, K., Dart, A. \& Tesluk, H. (1993) Reconstruction of calvarial defects with anorganic bovine bone mineral (Bio-oss) in a rabbit model. Journal of Craniofacial Surgery 4: 79-84.

Vignoletti, F., Matesanz, P., Rodrigo, D., Figuero, E., Martin, C. \& Sanz, M. (2012) Surgical protocols for ridge preservation after tooth extraction. 
A systematic review. Clinical Oral Implants Research 23: 22-38.

Waasdorp, J. \& Feldman, S. (2011) Bone regeneration around immediate implants utilizing a dense PTFE membrane without primary closure: a report of 3 cases. Journal of Oral Implantology. [Epub ahead of print].

Yun, J.H., Jun, C.M. \& Oh, N.S. (2011) Secondary closure of an extraction socket using the double membrane guided bone regeneration technique with immediate implant placement. Journal of Periodontal \&) Implant Science 41: 253-258. 